\title{
Giant inguinoscrotal hernia in children: two rare cases
}

\author{
Jayalaxmi Shripati Aihole*
}

\begin{abstract}
Background: Inguinal hernia is one of the most common surgical diseases encountered in adults as well as in children. Though rare, giant inguinoscrotal hernias are reported in adults, however, are rarely reported in children.

Case presentation: Here is a report of two rare cases of giant inguinoscrotal hernias in children managed successfully.

Conclusion: Giant inguinoscrotal hernias in children are rare and should be referred early and managed in a tertiary care paediatric centre.
\end{abstract}

Keywords: Giant inguinoscrotal hernia, Massive inguinoscrotal hernia, Herniotomy

\section{Background}

The definition, the types as well as surgical management of giant inguinoscrotal hernias in adults have been well published in the literature; its presentation in children has rarely been reported.

\section{Case presentation}

\subsection{Case 1}

A four-year-old male child brought to us by parents with history of huge left inguinoscrotal swelling, noticed after a month of age and gradually started increasing in size to attain the present size of massive hernia around $25 \mathrm{~cm} \times 12 \mathrm{~cm}$ reaching up to mid-thigh on standing (Type 1) (Fig. 1a). The swelling was partially reducible without any associated tenderness. The child never had any episodes of irreducibility, pain, bowel or bladder dysfunction or any associated chronic cough. His weight and height were appropriate for his age. Having normal biochemical and haematological parameters operative intervention was planned.

Giant inguinoscrotal hernia was reduced completely under general anaesthesia (Fig. 1b); thick and huge indirect inguinal hernia sac was felt; hence, the standard

\footnotetext{
*Correspondence: jayalaxmisaihole@yahoo.com; jaihole4@gmail.com
} Department of Paediatric Surgery, IGICH, Bangalore, Karnataka, India
Fergusons herniotomy was performed by exposing the inguinal canal via inguinal skin crease $1.5 \mathrm{~cm}$ incision, giant; thick inguinoscrotal hernia sac was isolated meticulously from the spermatic cord structures and the proximal sac was ligated and transfixed at the normal looking deep inguinal ring (Fig. 2a, b), the excessive distal sac was trimmed and wound was closed in layers without any difficulty (Fig. 2c, d). Child was started on feeds after $4 \mathrm{~h}$ and discharged after $12 \mathrm{~h}$. The child is doing well on three year's follow-up.

\subsection{Case 2}

A five-year-old male child born by full-term vaginal delivery with a birth weight of $2.8 \mathrm{~kg}$; brought to us with history of right inguinoscrotal swelling noticed 10 days after birth. The swelling has gradually progressed to attain the present size of $22 \mathrm{~cm} \times 10 \mathrm{~cm}$, partially reducible hernia on right inguino scrotal region reaching up to mid-thigh on standing posture (Type 1) (Fig. 1b). Child was clinically stable, without any history of irreducibility of the swelling or any other anomalies with normal bowel and bladder functions. Having routine laboratory investigations including cardiac evaluation normal, child was managed by right hernitomy through inguinal skin crease incision under general anaesthesia excising excessive distal sac, after ligation of proximal sac at the 


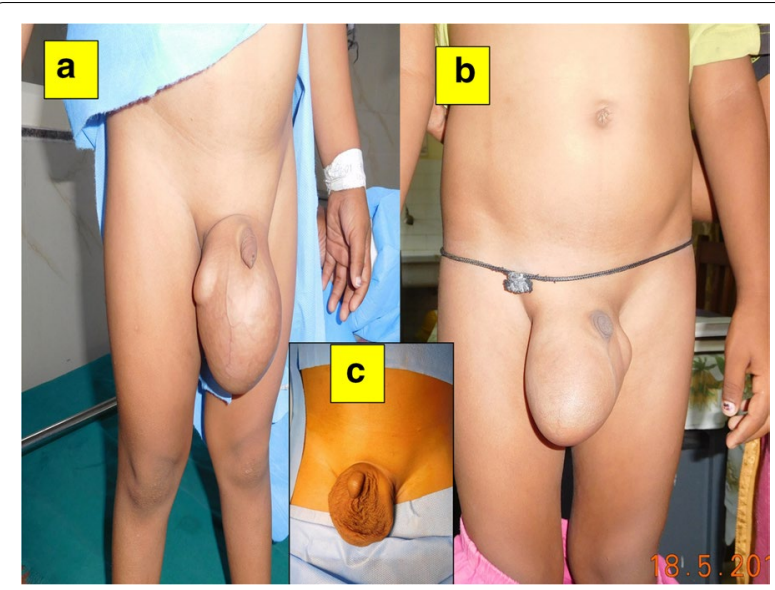

Fig. 1 a Clinical picture of Left giant inguinoscrotal hernia. b Clinical picture of Right giant inguinoscrotal hernia. c Reduction of hernial contents under general anaesthesia

level of normal looking deep inguinal ring with absorbable suture and wound was closed uneventfully. Child was discharged next day. Histopathological examination of distal sac revealed fibrous wall. The child is doing well on two year's follow-up (Fig. 2e, f).
Both children withstood the surgical procedure well.

\section{Discussion}

The processus vaginalis a 'tongue or finger' of the peritoneum develops at around 12th week of gestation helps in testicular descent which usually regresses at around 36 to 40th week. In few neonates, this process is incomplete, hence, patent processus vaginalis (PPV) remains, $20 \%$ of which will close by first year of age $[1,2]$.

The closure of the PV on the left side precedes the right; therefore, it is not surprising that $60 \%$ of congenital inguinal hernia noticed on the right side [1, 2].

Isolated inguinal and inguinoscrotal hernias are common in infants as well as in children, which can be managed successfully with standard Fergusons technique. Though rare, Giant inguinoscrotal hernias in adults have been reported in the literature, but, however, their occurrence in children has rarely been reported as well as their definition.

Due to the massive size of giant inguinoscrotal hernias, child will have discomfort in walking, playing, sitting and lying down; hence, affecting the quality of life as well as having impact on psychological and social life. These patients might have bowel or bladder disturbances [3-5].

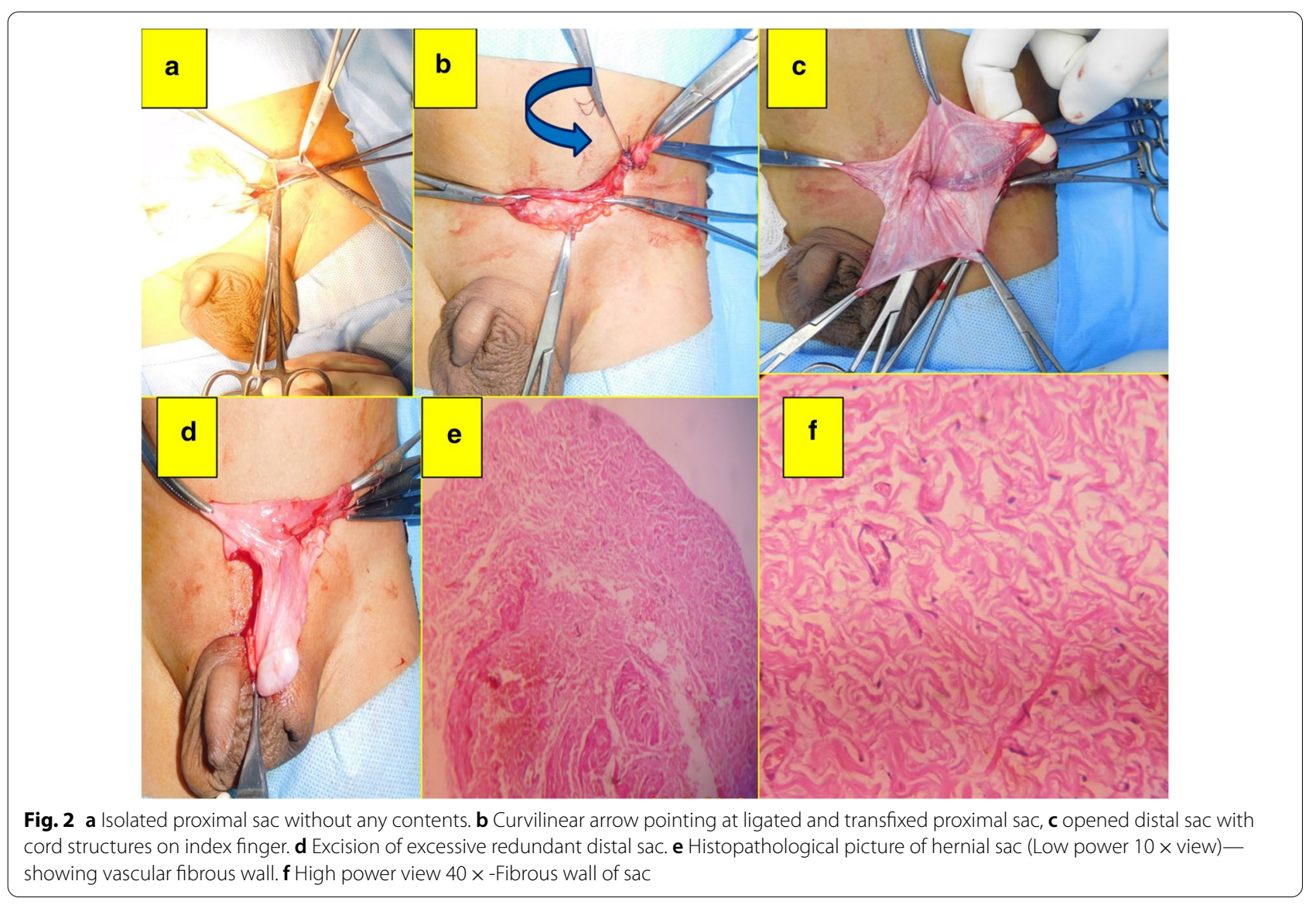


The reason for late presentation may be due to parental or caretaker's ignorance or may be due to fear of exposing the child for surgical procedure.

As per new classification system in adults; giant inguinoscrotal hernias have been classified into 3 types as seen on standing position. Type 1 inguinoscrotal hernia extending to mid inner thigh, type 2 extending midway between mid inner thigh to supra patellar line; type 3 extending to superior border of patellar bone [3-5]; however, its practical applicability in children is yet to be ascertained.

These cases should be operated immediately to avoid the morbidity like ulceration over the swelling or incarceration [3-5].

Giant inguinoscrotal hernias pose surgical challenge due to resultant cardio respiratory compromise following sudden increase in intra-abdominal pressure during reduction in herniated viscera especially in adults requiring post-operative mechanical ventilation following tension-free mesh hernioplasty [3-5], however, such difficulties were not encountered in these two children.

Author had two male children presenting with asymptomatic huge inguinoscrotal hernia type 1, without having any symptoms or comorbidities, both were uneventfully managed by standard Fergusons herniotomy in a tertiary care neonatal and paediatric centre in southern India.

\section{Conclusion}

Awareness from the parents, care takers, as well as primary health professionals, is required for earlier management of such children in a tertiary care paediatric centre avoiding morbidity as well as mortality.

Abbreviation

PPV: patent processus vaginalis.
Acknowledgements

Author would like to thank all her paediatric surgical colleagues and all the staffs of IGICH, Bengaluru, karnataka.

Authors' contributions

JSA has contributed to the article. The author read and approved the final manuscript.

Funding

None.

Availability of data and material

Yes on request.

\section{Ethics approval and consent to participate}

Indira Gandhi child health institute's ethical committee, Bengaluru, Karnataka, India. IGICHirb0345673, on 1/12/19. Written consent obtained from parents.

\section{Consent for publication}

Written and verbal consent taken from parents.

\section{Competing interests}

The author declares that he has no competing interests.

Received: 9 July 2020 Accepted: 14 December 2020

Published online: 07 January 2021

\section{References}

1. Grosfeld JL (1989) The current concepts in inguinal hernias in infants and children. World J Surg 13:506-515

2. Grosfeld JL, Minnick K, Shedd F, West KW, Rescorla FJ, Vane DW (1991) Inguinal hernia in children: the factors which affected the recurrence in 62 cases. J Paed Surg 58:283-287

3. Karthikeyan VS, Sistla SC, Ram D, Ali SM, Rajkumar N (2014) Giant inguinoscrotal hernia-report of a rare case with literature review. Int Surg 99:560-564

4. El Saadi AS, Al Waden AH, Hamerna S (2005) Approach to a giant inguinoscrotal hernia. Hernia 9:277-279

5. Anadolulu Ai, Kafadar MT, Gerçel G (2019) Definition of giant inguinoscrotal hernias in infants and evaluation of reliable surgical approach in a single-center study. Ann Med Surg (Lond) 45:127-129

\section{Publisher's Note}

Springer Nature remains neutral with regard to jurisdictional claims in published maps and institutional affiliations.

\section{Submit your manuscript to a SpringerOpen ${ }^{\odot}$ journal and benefit from:}

- Convenient online submission

- Rigorous peer review

- Open access: articles freely available online

- High visibility within the field

- Retaining the copyright to your article

Submit your next manuscript at springeropen.com 